\title{
AN INTERNATIONAL NETWORK OF CORAL REEF ECOSYSTEM OBSERVING SYSTEMS (I-CREOS)
}

\author{
Russell E. Brainard ${ }^{(1)}$, Scott Bainbridge ${ }^{(2)}$, Richard Brinkman ${ }^{(2)}$, C. Mark Eakin ${ }^{(3)}$, Michael Field ${ }^{(4)}$, \\ Jean-Pierre Gattuso $^{(5)}$, Dwight Gledhill ${ }^{(6)}$, Lew Gramer ${ }^{(6)}$, Alison Green ${ }^{(7)}$, Jim Hendee ${ }^{(6)}$, Ronald K. Hoeke ${ }^{(8,1)}$, \\ Sally J. Holbrook ${ }^{(9)}$, Ove Hoegh-Guldberg ${ }^{(10)}$, Marc Lammers ${ }^{(11,1,8)}{ }^{\text {, Derek Manzello }}{ }^{(6)}$, Margaret McManus ${ }^{(12)}$, \\ Russell Moffitt $^{(8,1)}$, Mark Monaco ${ }^{(13)}$, Jessica A. Morgan ${ }^{(3)}$, David Obura ${ }^{(14)}$, Serge Planes ${ }^{(15)}$, Russell J. Schmitt ${ }^{(9)}$, \\ Craig Steinberg ${ }^{(2)}$, Hugh Sweatman ${ }^{(2)}$, Oliver J. Vetter $^{(8,1)}$, Clive Wilkinson ${ }^{(16)}$, Kevin B. Wong ${ }^{(1)}$ \\ (1) NOAA (National Oceanic and Atmospheric Administration) Pacific Islands Fisheries Science Center, Coral Reef \\ Ecosystem Division, 1125-B Ala Moana Blvd., Honolulu, HI 96814, USA, \\ Email: Rusty.Brainard@noaa.gov; Ronald.Hoeke@noaa.gov; Russell.Moffitt@noaa.gov; Kevin.Wong@noaa.gov \\ ${ }^{(2)}$ Australian Institute of Marine Sciences, Townsville, Cape Cleveland Road, Cape Ferguson, Townsville, \\ Queensland4810 Australia, Email: s.bainbridge@aims.gov.au; r.brinkman@aims.gov; \\ c.steinberg@aims.gov.au; h.sweatman@aims.gov.au \\ (3) NOAA (National Oceanic and Atmospheric Administration) Coral Reef Watch, Silver Spring MD 20910-3282. USA., \\ Email: Mark.Eakin@noaa.gov; jessica.morgan@noaa.gov \\ (4) United State Geological Survey, 345 Middlefield Rd, Menlo Park, California 94025 USA, Email: mfield@usgs.gov \\ ${ }^{(5)}$ CNRS (Centre National de la Recherche Scientifique), Université Pierre et Marie Curie - Paris 6, Laboratoire \\ d'Océanographie, Chemin du Lazaret, 06230 Villefranche-sur-Mer, France, Email: gattuso@obs-vlfr.fr \\ (6) NOAA (National Oceanic and Atmospheric Administration) Atlantic Oceanographic and Meteorological Laboratory, \\ 4301 Rickenbacker Causeway, Miami, FL 33149, USA, Email: gledhill@noaa.gov; Lew.Gramer@noaa.gov; \\ jim.hendee@noaa.gov; Derek.Manzello@noaa.gov \\ (7) The Nature Conservancy, Asia Pacific Resource Center, 51 Edmondstone Street, South Brisbane, Queensland 4101 \\ Australia, Email: agreen@tnc.or \\ (8) Joint Institute for Marine and Atmospheric Research, University of Hawaii (HU), 1125-B Ala Moana Blvd., \\ Honolulu, HI 96814, USA, Email: hoeke@hawaii.edu; lammers@hawaii.edu \\ (9) University of California at Santa Barbara, California 93106-6150 USA, Email: holbrook@lifesci.ucsb.edu; \\ ${ }^{(10)}$ University of Queensland, Brisbane, St-Lucia, Queensland 4072, Australia, Email: oveh@uq.edu.au \\ ${ }^{(11)}$ Hawaii Institute of Marine Biology, University of Hawaii, P.O. Box 1346, Kaneohe, Hawaii 96744, USA; \\ Email: lammers@hawaii.edu \\ ${ }^{(12)}$ UH (University of Hawaii) School of Earth Science and Technology, 1680 East West Road, POST Bldg. \#401, \\ Honolulu, HI 96822, USA, Email: mamc@ hawaii.edu \\ ${ }^{(13)}$ NOAA (National Oceanic and Atmospheric Administration) Center for Coastal Monitoring and Assessment, \\ 1305 East West Highway, Rm. 8419, Silver Spring, MD 20910, USA, Email: mark.monaco@noaa.gov \\ (14) Coastal Ocean Research and Development in the Indian Ocean, International Union for the Conservation of Nature, \\ Climate Change and Coral Reefs Marine Working Group, 99 Lamu (80500), Kenya, Email: dobura@cordioea.org \\ ${ }^{(15)}$ Centre de Recherches Insulaires et Observatoire de l'Environnement de Polynésie Française, BP 1013, \\ Papetoai, Moorea, Polynésie Française, France, Email: serge.planes@criobe.pf \\ (16) Global Coral Reef Monitoring Network, PO Box 772, Townsville 4810 Australia, \\ Email: clive.wilkinson@rrr.org.au
}

\section{ABSTRACT}

Coral reefs are complex, biologically diverse, and highly-valued ecosystems that are declining worldwide due to climate change and ocean acidification, overfishing, land-based sources of pollution, and other anthropogenic threats. To assist policy makers and resource managers at international, national, and local levels in effectively implementing ecosystem approaches to sustainable management and conservation of coral reefs and their biodiversity, it is necessary to have timely, unbiased integrated ecosystem observations about the conditions of coral reefs and the complex physical and biogeochemical processes
\end{abstract}

supporting them. To provide these interdisciplinary ecosystem observations, an International network of Coral Reef Ecosystem Observing Systems (I-CREOS) is proposed that will organize and build upon existing coral reef observation systems being developed around the globe.

This paper uses examples of some developing observation systems to demonstrate some of the approaches and technologies available for acquiring biological, physical, and geochemical observations using combinations of: visual surveys, moored instrument arrays, spatial hydrographic and water quality surveys, satellite remote sensing, and 
hydrodynamic and ecosystem modeling. This fledgling, and hopefully expanding, network of observing systems represents the early stages of an integrated ecosystem observing system for coral reefs capable of providing policy makers, resource managers, researchers, and other stakeholders with essential information products needed to assess various responses of coral reef ecosystems to natural variability and anthropogenic perturbations.

While significant challenges and gaps in the I-CREOS network remain, it demonstrably fulfills the requirements of an operational, integrated, interdisciplinary, coastal component of GOOS (Global Ocean Observing System). Continued support, further development, and open expansion of this emerging network are encouraged and needed to ensure the continually increasing value of the network's observational and predictive capacity. With common goals to maximize versatility, accessibility, and robustness, the existing infrastructure and capacity provide a foundation by which increased global cooperation and coordination could naturally lead to a globally comprehensive I-CREOS.

\section{INTRODUCTION}

Coral reef ecosystems are among the most complex and biologically diverse of all marine ecosystems [1]. Coral species themselves constitute on the order of $\sim 1000$ species worldwide, but estimates for reef associates range between 1 and 9 million species [2]. Coral reefs provide economic and environmental services to hundreds of millions of people in terms of shoreline protection; areas of natural beauty and recreation; and sources of food, pharmaceuticals, chemicals, jobs and revenue [3, 4 and 5]. At many oceanic island and coastal areas, coral reefs and the resources they provide are central to the cultural practices of the indigenous peoples who have evolved around them for millennia [6, 7 and 8].

Coral reefs are also among the most sensitive and threatened marine ecosystems [9, 10 and 11]. Coral reef ecosystems worldwide have been deteriorating at alarming rates due both to local anthropogenic pressures, such as over-exploitation [12], habitat destruction [13], disease [14 and 15], invasive species, land-based sources of nutrients, sediments, pollution [16], marine debris, and impacts associated with global climate change [17 and 18], especially increased ocean temperatures [19 and 20], and ocean acidification [21 and 22]. Over the past 30 years, coral cover at many Caribbean reefs has decreased by up to $80 \%$ [23], even healthy reefs have suffered measurable degradation [24]. These declines are directly associated with loss of biodiversity, associated ecosystem services, and the economic factors that reefs provide to society.

\section{INFORMATION NEEDS FOR RESOURCE MANAGEMENT AND CONSERVATION}

Marine resource managers must make decisions that allow humans to sustainably interact with and use complex ecosystems while ensuring long-term conservation and viability for future generations. Managers also must track the effects of interventions in an adaptive management framework and justify their actions where these impinge on peoples' lives. Internationally, there has been recognition of the need to develop ecosystem approaches to management (EAM) that account for the complex interrelationships between abiotic environmental factors driving oceanic, atmospheric, and terrestrial processes and their interaction with living organisms on systematic ecological levels [25].

While there has been widespread agreement on the need for EAM, there continues to be debate on how best to implement them. There is a clear need for unbiased, credible, and timely scientific information documenting the status and trends of ecosystem condition [26]. For coral reefs, the Global Coral Reef Monitoring Network (CGRMN) has published a series of "Status of Coral Reefs of the World" reports since 1998 [27] and continues to provide subjective regional assessments of the status of the world's reefs. In its 2008 report [11], the GCRMN was unable to factor in global climate change in future predictions because of underlying uncertainty and lack of local impact data. However, the transition toward EAM is occurring as traditional challenges (e.g. fishing, coastal development) are being exacerbated by the significant global threats imposed by ocean warming, ocean acidification, and sea level rise. In light of these increasing challenges, there is a heightened need for increased commitment for more detailed, quantitative long-term interdisciplinary integrated ecosystem observations of coral reefs and the dynamic processes influencing them.

\section{EXAMPLES OF EXISTING CORAL REEF ECOSYSTEM OBSERVING SYSTEMS}

In this section, we describe some of the larger international coral reef ecosystem observing systems to highlight common elements, which should naturally serve as the basis for establishing I-CREOS (International network of Coral Reef Ecosystem Observing Systems).

\subsection{U.S. Pacific and Atlantic - NOAA CREIOS}

As part of the U.S. Integrated Ocean Observing System (IOOS), the National Oceanic and Atmospheric Administration's (NOAA) Coral Reef Conservation Program established the Coral Reef Ecosystem Integrated Observing System (CREIOS) [28] to better understand the condition of and processes influencing the health of coral reef ecosystems, and to provide this 
information to resource managers and policy makers to assist them in making timely, science-based management decisions to conserve coral reefs. CREIOS provides a diverse suite of long-term ecological and environmental observations and information products over a broad range of spatial and temporal scales.

For the U.S. Pacific Islands, CREIOS supports integrated ecosystem assessments consisting of benthic habitat mapping and ecological, oceanographic, and water quality monitoring over diverse spatial (island, archipelago, ocean basin) and temporal (diurnal, seasonal, interannual, climate) scales [29]. NOAA's Coral Reef Ecosystem Division (CRED) leads the Pacific Reef Assessment and Monitoring Program (Pacific RAMP) in conducting biennial monitoring surveys of the coral reef ecosystems around $\sim 50$ islands, atolls, or reefs in the Hawaiian, Samoan, and Mariana Archipelagos and the Pacific Remote Island Areas in the central Pacific [30] (Fig. 1). These interdisciplinary Pacific RAMP surveys include: multibeam benthic habitat mapping [31], visual rapid ecological assessments of fish [32], corals [33] and coral disease [34], other macroinvertebrates, and algae [35 and 36], towed-diver surveys of benthic composition and condition [37] and abundance of ecologically and/or economically important large fish $(>50 \mathrm{~cm}$ Total Length) and macroinvertebrate taxa, hydrographic surveys, and water quality sampling. Instrumented moorings provide time series observations of oceanographic conditions between biennial Pacific RAMP surveys [29]. By using consistent methods across diverse gradients of biogeography, environmental conditions, and human impacts (ranging from pristine to

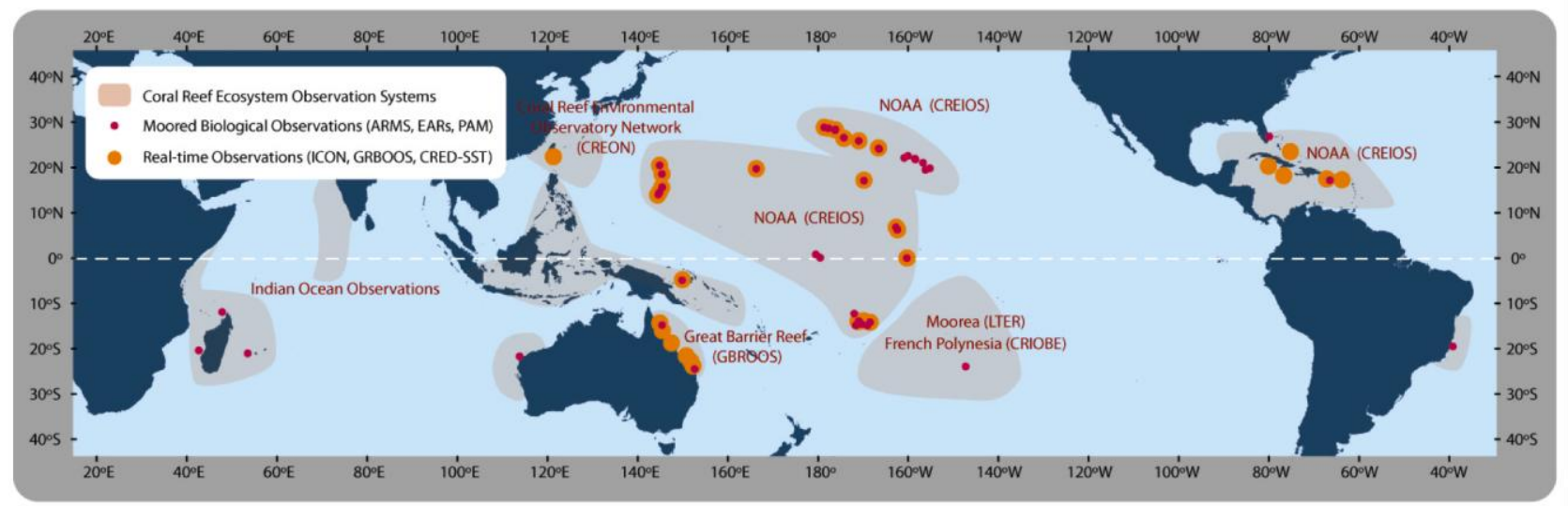

Figure 1. Map showing locations of some existing large-scale I-CREOS programs and some of the key observing system components discussed in this document. A) Locations of moored instrumentation from USGS (U.S. Geological Survey), Moorea LTER MCR (Moorea Coral Reef Long Term Ecological Research Site), GBROOS, ICON (Integrated Coral Observing Network), and NOAA CREIOS moorings. B) Locations of biological monitoring in the Pacific Islands.

degraded), Pacific RAMP provides an unprecedented opportunity for comparative analyses of reef ecosystems across the Pacific.

NOAA's Center for Coastal Monitoring and Assessment (CCMA) conducts integrated coral reef ecosystem and mapping observations in the U.S. Caribbean [38, 39 and 40], including satellite and shipbased bathymetry and habitat mapping, visual assessment of fishes and macro-invertebrates, and monitoring of corals, coral diseases, sessile invertebrates, and algae. A stratified-random survey design is implemented to conduct long-term monitoring and complemented by grants to local partners to increase the frequency of sampling. Their work complements observations taken by NOAA's Integrated Coastal Observing Network (ICON) [41], whose instrumented stations take physical and chemical observations across the Caribbean. NOAA's
Coral Reef Watch complements the work in both basins with satellite observations that track physical parameters that influence the biology, chemistry, and ecosystem responses of coral reefs [42 and 43].

\subsection{Great Barrier Reef - GBROOS}

On the Great Barrier Reef (GBR) and as part of an Australia-wide Integrated Marine Observing System (IMOS), the GBR Ocean Observing System (GBROOS) [44] is deploying a range of ocean observing equipment to measure and monitor the impact of large-scale change on this iconic coral reef system (Fig. 1). The design includes updated remote sensing capacity with an X and L band remote-sensing station at Townsville, underway sampling equipment installed on multiple commercial and research vessels, a moored instrument array, and a series of sensor networks installed at seven reef sites. The experimental design for GBROOS aims to link the large-scale 
oceanic processes into the processes and impacts seen at reef and within reef scales. GBROOS monitors the inflow of cool and warm water intrusions from the ocean into the reef matrix. Series of moorings are located in pairs along the GBR, one of the pairs is located in deep water $(70-200 \mathrm{~m})$ on the continental slope and the other is located in shallower water (30-70m depth) on the shelf. The design allows water moving onto and across the shelf to be tracked. Sensor networks deployed at key reef sites include real-time sensors that match those on the moorings and so it becomes possible to track the impacts of oceanic events through the reef matrix into the reefs themselves. This, with the other observations, gives critical information about the functioning of the major current systems and the services they provide to reefs and to provide the data required to model potential impacts of thermal and other events on the corals. GBROOS links into the Australian Institute of Marine Science's (AIMS) Long-Term Monitoring Program (LTMP), which has been conducting extensive biological monitoring of corals and key fish and macroinvertebrates along and across the GBR since 1993 using visual scientific diver surveys [45].

\subsection{Moorea LTER}

The Moorea Coral Reef (MCR) Long Term Ecological Research (LTER) site is an interdisciplinary, landscape-scale program, established in 2004 and funded by the U.S. National Science Foundation, to improve understanding of processes that modulate ecosystem function and structure of coral reefs. The site consists of the complex of coral reefs that surrounds the $60 \mathrm{~km}$ perimeter of the island of Moorea in French Polynesia. Moorea is a small, triangular volcanic "high" island with an offshore barrier reef that forms a system of shallow (mean depth $\sim 5$ to $7 \mathrm{~m}$ ), narrow ( $\sim 1$ to $1.5 \mathrm{~km}$ wide) lagoons that encircle the island (Fig. 1). Scientists at the MCR LTER site record spatially-explicit time series measurements to describe decadal trends in biological aspects of the reef ecosystem and physical forcing functions. At each of three locations on the fore reef, a pair of instrumented sites has been established. These six instrumented sites are in close proximity $(<25 \mathrm{~m})$ to the fixed quadrats and transects where biological surveys monitor: rates of recruitment of corals; abundance and size/biomass of major reef constituents such as heterotrophic reef microbes, phyto- and zooplankton, algae, scleractinian corals, herbivores and other major reef invertebrates and fishes). Continuous physical oceanographic measurements at all six sites include ocean temperature (T), and at the three heavily instrumented sites also include conductivity, turbidity, pressure, wave height and direction and current velocity. Additional measurements of $\mathrm{T}$ and biotic surveys are conducted on the backreef and fringing reef at all six sites.
Thermistor strings are deployed at the entrance pass and in the center of Cook's Bay, and a local meteorological station provides surface environmental data.

\subsection{French Polynesia - CRIOBE}

At a broader spatial scale within French Polynesia, scientists from CRIOBE (Centre de Recherches Insulaires et Observatoire de l'Environnement de Polynésie Française) conduct biotic surveys of reefs annually at Moorea and biennially at 14 other high islands and atolls in five archipelagoes of French Polynesia and seven countries of the South Pacific (Fig. 1). Thermistors are deployed on the reefs of each island for continuous $\mathrm{T}$ measurement, and in 2008 sensors were deployed at Moorea, Tetiaroa, Tikehau, Nuku-Hiva, Tubuai, Marutea in French Polynesia and Cooks, Tonga, Wallis, Samoa, Niue, Kiribati to measure waves and currents, as well as $\mathrm{pH}$ and dissolved oxygen (DO) in some locations.

\subsection{Global - CREON}

During the past several years, the Coral Reef Environmental Observatory Network (CREON), a grass-roots community effort involving scientists from several coral reef research sites has emerged to share expertise on deployment of real-time environmental sensors for gathering data to address ecological processes at all scales. Current areas of interest include development of a robust physical network and cyberinfrastructure, as well as an interface for data access, integration and query across a network of sites where scientists can pose research questions requiring broadscale environmental data. Scientists from the GBROOS, MCR LTER site, NOAA, and the Kenting Coral Reef International LTER site in Taiwan have been participating in CREON. Three of the sites (GBROOS, MCR LTER, Kenting Coral Reef ILTER) currently are using the Open Source DataTurbine [46] software for real-time data streaming from a variety of sensors deployed on the reefs.

\subsection{Indian Ocean}

The Indian Ocean serves as an example for other regions with low capacity where different observing systems exist [11, 47, 48 and 49], and form a foundation for an integrated system, but significant barriers prevent full integration and widespread application of more technologically intensive methods. Biological monitoring of coral reefs occurs through multiple organizations and networks, all reporting to the GCRMN [11]. Physical oceanographic observations are coordinated through the Indian Ocean Observing System (IndOOS) and the CLIVAR (Climate Variability and Predictability)/GOOS Indian Ocean Panel [50]. Initial attempts are being made to coordinate these with ecosystem observations under the 
coastal-GOOS umbrella to link them to integrated monitoring of coral reef, mangrove, and seagrass ecosystems. Chemical observations are limited to a small number of laboratories (e.g. Reunion). These provide raw materials for establishment of an ICREOS in the Indian Ocean, particularly where remote sensing datasets and automated sensors can be deployed to fill gaps.

\section{BIOLOGICAL OBSERVATIONS OF CORAL REEF ECOSYSTEMS}

\subsection{Visual Surveys}

Since instruments that monitor biological parameters or surrogates typically require optical or other interfaces that degrade due to biofouling if not frequently serviced, most biological observations of coral reefs are collected during human-mediated visual or photographic surveys (Fig. 2a). Such efforts are often as part of on-going coral reef monitoring programs, such as those mentioned above along the GBR [ 44 and 45], in the Caribbean [51 and 52], across the Pacific Islands [29, 53, 54, 55, 56, 57 and 58], and globally [11 and 59]. Most of these on-going coral reef monitoring programs observe abundance (density), species composition, size frequency, and spatial distributions of fish and corals, and to a lesser extent macroalgae and target macroinvertebrate taxa (e.g. lobster, crownof-thorns seastars, giant clams, urchins, etc.). Historically, limited resources and taxonomic capacity, even in these existing large-scale coral reef monitoring programs, have prevented assessment of the diversity of the small cryptic organisms that comprise the majority of coral reef biodiversity. On-going coral reef monitoring programs are generally limited in their spatial and temporal coverage at global, regional, and local scales [11]. Ongoing advances in understanding of ecosystem dynamics are leading to increased use of
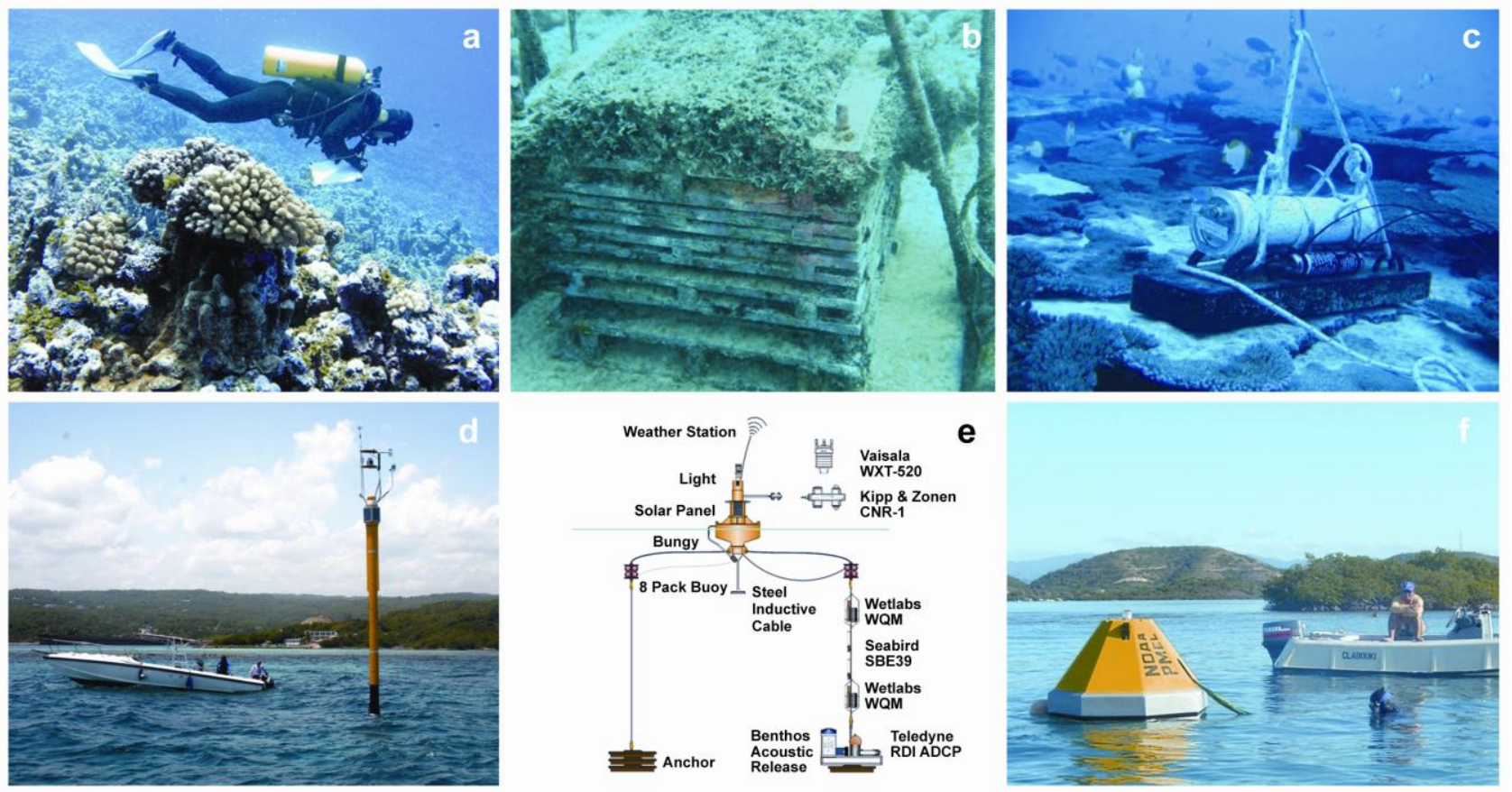

Figure 2. Examples of key biological (a-c) and physical (d-f) observing system components of I-CREOS. a) Visual surveys of reef fish, corals, invertebrates, and algae (Photo NOAA-CRED); b) ARMS at a forereef site in Hawaii (Photo NOAA-CRED); c) EAR (Ecological Acoustic Recorder) deployed at French Frigate Shoals, Northwestern Hawaiian Islands (Photo NOAA-CRED); d) ICON/CREWS (Coral Reef Early Warning System) station at Media Luna Reef, Puerto Rico (Photo J. Hendee); e) GBROOS Shelf mooring design; and f) $\mathrm{MAPCO}_{2}$ (Moored Autonomous $\mathrm{pCO}_{2}$ ) Buoy near Cayo Enrique Reef, La Parguera, Puerto Rico (Photo J. Hendee).

indicator-based assessments focused on key drivers relevant to managing phase shifts between coraldominated versus other ecological phases of reefs.

To address some of these challenges, the following technological approaches are being developed and implemented to more cost-effectively and continuously observe biota of coral reefs.

\subsection{Biodiversity Assessments - ARMS}

To address the limited ability of existing monitoring programs to assess and monitor the biodiversity of coral reefs, the Census of Coral Reef Ecosystems (CReefs) project of the Census of Marine Life has developed Autonomous Reef Monitoring Structures (ARMS) as systematic collecting devices to allow a 
global comparative baseline assessment of spatial patterns of cryptic invertebrate diversity [60]. ARMS are simple PVC structures designed to mimic the complexity of coral reef habitats and attract colonizing invertebrates (Fig. 2b). CReefs and Pacific RAMP have initiated a global array of 400 ARMS deployed in Hawaii, Samoa, Line and Phoenix Islands, Moorea, the GBR, Brazil, Panama, Papua New Guinea, the western Indian Ocean, and Florida, and planned deployments for 2010 in Puerto Rico, Cayman Islands, Belize, and Taiwan (Fig. 1). Efforts to develop genetic pyrosequencing techniques will further increase the efficiency, cost effectiveness, and comparability of this approach.

\subsection{Passive Acoustic Monitoring - EARs}

Ecological Acoustic Recorders (EARs) are digital passive acoustic devices that record ambient sounds have been developed specifically for monitoring marine mammals, fish, crustaceans, other soundproducing marine life, and human activity in marine habitats. (Fig. 2c). EARs provide a unique ability to cost-effectively monitor remote reefs during the intervals between visual biological surveys [61]. Tools are being developed to acoustically assess biological processes, community structure, and ecological stability of coral reefs [62]. Anthropogenic sounds (e.g. boat engines, blast fishing and anchor chains) are also readily detectable, enabling EARs to also monitor human activities.

\subsection{Monitoring Physiological Stress in Corals - PAM Fluorometry}

Although research has been conducted to determine the physiological mechanisms underlying coral bleaching [63, 64 and 65], few efforts have monitored the coralzooxanthellae holobiont and the coincident environmental factors during bleaching episodes. Pulse-amplitude-modulating (PAM) fluorometry has recorded indicators of photosystem II inactivation in corals during up to a month prior to SST-based bleaching alerts [66], suggesting that PAM fluorometry may be an important observing system tool for assessing reef conditions.

\section{PHYSICAL AND CHEMICAL OBSERVATIONS OF CORAL REEF ECOSYSTEMS}

The emerging I-CREOS network uses a diverse suite of capabilities to observe the physical and chemical processes influencing coral reef ecosystems: A) moored instrument arrays to provide high resolution time series; B) spatial hydrographic and water quality surveys to assess spatial patterns and structure; C) remote sensing to provide spatial and temporal observations of surface processes; and D) hydrodynamic and ecosystem models to provide ecoforecasts and predictions.

\subsection{Moored Instrument Arrays}

The following examples highlight some of the moored instrument arrays in the Pacific Islands, Australia, and the Caribbean designed to:

- Understand the role physical and chemical processes play in structuring the distribution, abundance, diversity, and health of coral reef ecosystems;

- Characterize the variability of oceanographic and water quality conditions that influence the health of coral reef ecosystems;

- Understand the ecological effects of episodic disturbances, climate change, and ocean acidification;

- Understand the linkages between the large oceanicscale, reef-scale, and within reef-scale processes;

- Provide data assimilation and validation of hydrodynamic and ecological forecast "ecoforecast" models;

- Acquiring real-time observations to better coordinate sampling, research, and management.

\subsubsection{CREIOS Moorings}

Moored Coral Reef Early Warning System (CREWS) and SST buoys across the Pacific Islands [29] and Integrated Coral Observing Network (ICON) stations [67] in the Caribbean transmit observations to the CREWS expert software originally produced to monitor coral bleaching [68]. The CREIOS network of in situ telemetering instrumentation provides time series observations of $\mathrm{T}$, salinity $(\mathrm{S})$, photosynthetic active radiation (PAR), ultraviolet radiation (UV-B), air temperature $\left(\mathrm{T}_{\text {air }}\right)$, barometric pressure, and wind velocity [29]. The instrumental architecture for ICON stations has been designed to perform ecoforecasts and MPA (Marine Protected Area) decision support [67 and 69]. Higher resolution data from surface buoys and subsurface moorings are downloaded upon instrument recovery. In addition to 23 telemetered surface buoys, 613 subsurface moorings across the Pacific Islands record observations of: T, S, currents, ambient sounds, waves, tides, and indices of cryptic biodiversity [29]. More intensive short-term instrument deployments are made to examine site specific processes and to validate fine-scale hydrodynamic models [29]. NOAA's Coral Reef Information System (CoRIS) provides information and data discovery tools for near-real-time and archived data products.

\subsubsection{GBROOS Moorings}

The GBROOS moorings detect and monitor cold and warm water intrusions from the Coral Sea into and 
onto the GBR reef matrix. A review of the oceanographic vulnerability of the GBR to climate change [70] formed the basis for the GBROOS design. The main components of GBROOS consist of pairs of deep water moorings arranged north to south along the length of the GBR and a series of sensor networks at individual reefs. The mooring array consists of four pairs of moorings located along the GBR, with one pair on the continental slope $(70-300 \mathrm{~m})$ and the other pair on the continental shelf $(30-70 \mathrm{~m}$, Fig. 2e). The design aims to detect the movement of oceanic water up the continental slope and onto the shelf and so give information about upwelling events and the strength and direction of the oceanic currents as they impinge on the reef. The paired moorings in the northern part of the GBR are designed to measure the northward current flow outside the reef matrix and the inflow of that water through the ribbon reefs; the moorings in the central region will measure water intruding from the deeper slope onto the shelf. The reef matrix is open in this region, so water is able to move up and across the shelf. The moorings in the southern area are positioned to measure the southward current flow outside the reef matrix via the deep-water mooring and through the main GBR lagoon using the inshore mooring. Three moorings have been deployed around Heron and One Tree Islands in the south, two on the shelf and one on the slope. These will capture the complex regional currents where a recirculation of the East Australian Current often occurs and subsurface intrusions often stratify the shelf.

As part of the GBROOS project, sensor networks will be deployed at four island sites (Heron and One Tree Islands, Orpheus Island, and Lizard Island) and three reefs (Davies, Rib and Myrmidon). Much of the equipment is relocatable and can be deployed to provide real-time information down to the scale of individual coral heads. Initial sensors measure T, $\mathrm{S}$ and depth, but the infrastructure supports other sensors, such as video, $\mathrm{pCO}_{2}$, and PAR. The shelf moorings will be upgraded to real-time but the slope moorings will $\log$ data over 6 month servicing intervals. The shelf moorings typically have a bottom-mounted acoustic Doppler current profiler (ADCP; waves and current profiles) and a series of Water Quality Monitors (WQM, measuring T, conductivity, depth, turbidity, fluorescence, DO) and T up the mooring. On the surface is a radiometer (select buoys only) measuring incoming and outgoing short and long wave radiation, and a weather station. The deep-water slope moorings are similar but without the surface instrumentation. All moorings are serviced every six months and data are downloaded.

The sensor network installations comprise a base station installed on a permanent structure on reef towers that have direct communication to shore. A series of 6-m poles around the reef edge talk back to the base station and form the on-reef wireless network. Buoys located on the reef talk to the nearest network pole, which in turn passes the data to other poles and back to the base station. The solar powered buoys have a controller that interfaces a series of sensors, including conductivity, temperature and depth. Weather stations and WQMs will be added in the near future. The versatile system uses multiple communication protocols to support a range of sensors and observations. The sensor network is internet protocolbased to allow remote control of the instruments and the possibility of adaptive sampling, remote monitoring, and other "smart" sensor applications, such as webcams. GBROOS data are made available through a range of services, including Open Source DataTurbine [46], an OPeNDAP (Open-source Project for a Network Data Access Protocol) server, and via web pages. The data turbine software is used for realtime observations, as also used by CREON.

\subsubsection{Moorea LTER Mooring}

The relatively small island of Moorea is among the most instrumented reef systems in the South Pacific. Oceanographic instruments are deployed on each of the three sides of the island and they have revealed significant information about the substantial differences in physical regimes (especially offshore wave climate) impinging on the reef ecosystem around the island. Like all other reef ecosystems, the coral reefs on Moorea are greatly influenced by physical forcing. Waves that hit the barrier reef of the island drive circulation patterns of the lagoons [71], and large waves for prolonged periods are also capable of causing structural damage or death of the foundation coral species. The north shore is affected by moderate swell in the Austral summer generated by North Pacific storms and the south shore receives large swells (up to $9.5 \mathrm{~m}$ ) during the winter generated from the Southern Ocean.

\subsubsection{Caribbean Moorings}

The SEAKEYS (Sustained Ecological Research Related to Management of the Florida Keys Seascape) Network [72] is one of the longest records of meteorological, sea temperature, and salinity observations from a coral reef in the greater Caribbean region [73]. These observations are used to validate satellite-monitoring algorithms designed to provide coral bleaching alerts [74], among various applications. With this network and the CREWS software as a model [67], NOAA's Atlantic Oceanographic and Meteorological Laboratory (AOML) initiated efforts to establish a physical monitoring network across the Caribbean [75] by developing a pylon mooring design for ICON that moves dynamically with heavy wind and seas (Fig. 2d). ICON presently has stations in the 
Bahamas, U.S. Virgin Islands, Puerto Rico, Jamaica, Florida, and Cayman Islands. NOAA has also established Moored Autonomous $\mathrm{pCO}_{2}$ (MAPCO2) buoys in Puerto Rico and Hawaii to: 1) standardize approaches for monitoring, assessing, and modeling the impacts of acidification on coral reefs; 2) identify critical thresholds, impacts, and water chemistry trends necessary for developing ecoforecasts; 3 ) characterize the spatial and temporal variability in carbonate chemistry in coral reef environments; and 4) provide data and information to facilitate an alert system based on ecoforecasting for acidification stress to coral reefs (Fig. 2f).

The Caribbean Coastal Ocean Observing System (CariCOOS) is being implemented collaboratively through the Universities of Puerto Rico and the Virgin Islands. Through extensive consultations with stakeholders and ratification through the Caribbean Regional Association of IOOS, priorities include winds, waves, currents, water quality, coastal inundation, and erosion. CariCOOS is implementing a coordinated effort coupling ocean observing and numerical modeling to meet these priorities.

\subsection{Spatial Hydrographic and Water Quality Surveys}

Hydrographic surveys are performed during Pacific RAMP research cruises to provide detailed spatial assessments of oceanographic and water quality conditions influencing reefs around of each of the reefs of the U.S. Pacific Islands [29]. Surveys include: closely-spaced shallow water CTDs (ConductivityTemperature-Depth) in nearshore reefs $(0-30 \mathrm{~m})$ and deep-water CTDs $(0-500 \mathrm{~m})$ in surrounding waters to provide vertical profiles of conductivity, T, pressure, beam transmittance, DO, fluorescence, and turbidity; and water sampling for analysis of chlorophyll $a(\mathrm{Chl}$ $a$ ), nutrients (phosphate $\left(\mathrm{PO}_{4}^{-3}\right)$; silicate $\left(\mathrm{Si}(\mathrm{OH})_{4}\right)$; nitrate $\left(\mathrm{NO}_{3}^{-}\right)$; nitrite $\left.\left(\mathrm{NO}_{2}^{-}\right)\right)$, salinity, dissolved inorganic carbon (DIC), and total alkalinity (TA). Water sample depths are typically 1, 10, 20 and 30 meters in nearshore environments, and 3, 80, 100, 125, and 150 meters for offshore environments. Shipboard surveys of surrounding waters continuously provide current profiles, near-surface $\mathrm{T}$ and $\mathrm{S}, \mathrm{T}_{\text {air }}$, wind velocity, barometric pressure, and relative humidity while the vessel is underway.

\subsection{Satellite Remote Sensing of Threats to Coral Reefs}

Polar-orbiting satellites provide near-real-time observations across the globe with relatively low spatial (10s of $\mathrm{km}$ ) and temporal (4x daily) resolution, which NOAA's Coral Reef Watch (CRW) uses to monitor SST and other parameters influencing reef health. CRW products include: near-real-time global 0.5-degree night-time SST and anomalies, coral bleaching HotSpots and Degree Heating Weeks (DHW), updated twice weekly [68 and 76] (Fig. 3). HotSpots are the positive anomaly of SST that exceeds the maximum monthly mean for each $50-\mathrm{km}$ pixel, thus identifying regions that are currently undergoing thermal stress. By accumulating these SST (Sea Surface Temperature) anomalies, the DHW provides a measure of the cumulative thermal stress that corals experience. NOAA issues coral bleaching alerts via email when HotSpots or DHW values near a reef become positive and again when DHW values reach thresholds of 4 and $8^{\circ} \mathrm{C}$-weeks. The DHW index reliably provides regional-to-basin-scale information needed for coral reef managers and scientists to anticipate mass bleaching. The GBR Marine Park Authority has worked with partner agencies in Australia and with NOAA to produce the GBR-specific ReefTemp products that provide added predictive value for the GBR due to higher spatial and temporal resolution $(2 \times 2 \mathrm{~km}$, daily) and heating rate calculations [77]. High-resolution, multi-spectral visible images of changes in the color of coral reefs have been successfully applied to observe the extent of bleaching [78], but the cost and time required makes them less cost-effective in most locations.

NOAA is developing products to monitor parameters influencing the quantity and quality of light reaching corals: solar insolation, cloud cover, and turbidity. These observations will likely use geostationary satellites to provide more frequent sampling and better measures of variability, but with coverage limited to part of one hemisphere. International data sharing agreements will hopefully provide access to data for most coral reef areas. Since ocean color and turbidity are important in understanding how local sources of pollution (e.g. nutrients, sediments) influence reef ecosystems, research to use imagery in shallow water reef habitats will provide another important observing system capability.

\subsection{Hydrodynamic Modeling and Ecoforecasting}

NOAA has advanced efforts to synthesize satellite and modeled environmental datasets to derive synoptic estimates of changing ocean chemistry in response to ocean acidification [43 and 79] (Fig. 4). An experimental model provides estimates of surface aragonite saturation state $\left(\Omega_{\mathrm{arg}}\right)$, which imparts important controls on calcification rates of corals and other calcareous organisms, over broader spatial and temporal scales than shipboard observations alone. Daily fields of total alkalinity and $\mathrm{pCO}_{2, \mathrm{sw}}$ are computed through the coupling of modeled and remotely-sensed parameters to solve for surface ocean 


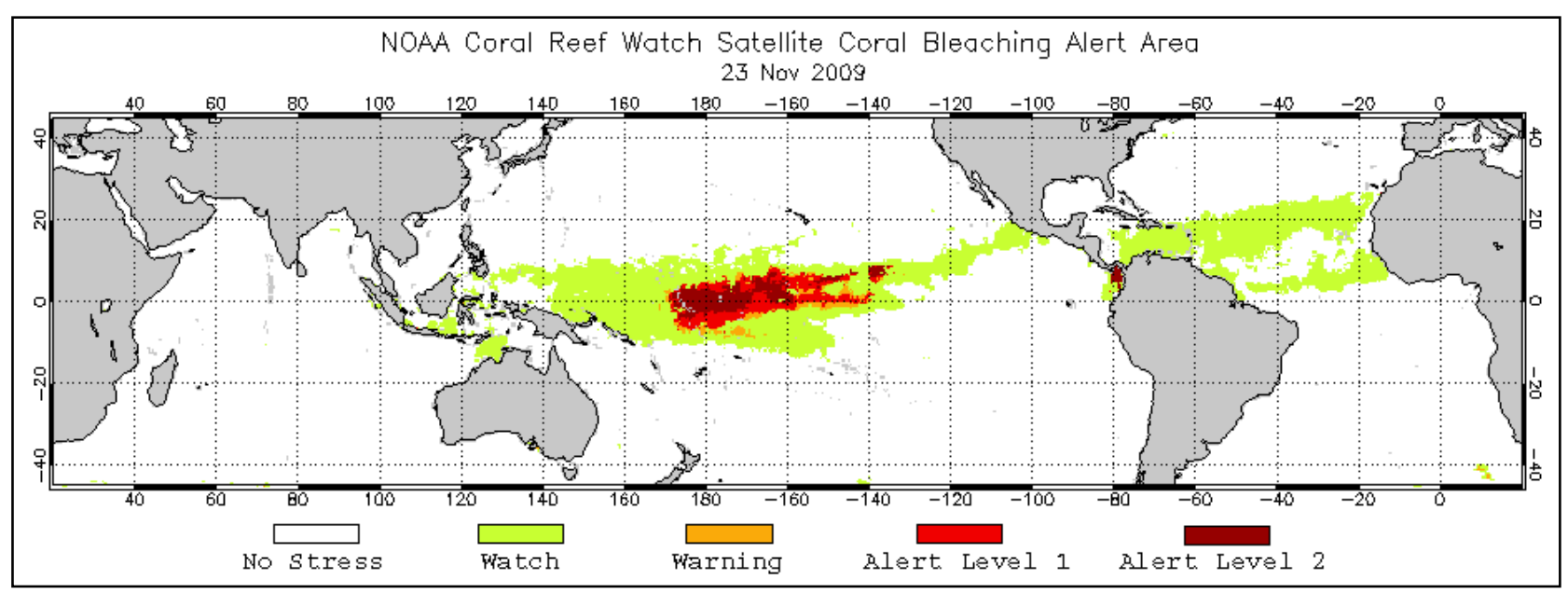

Figure 3. Global map of NOAA CRW Coral Bleaching Alert Area for 23 November 2009. The image shows a combination of HotSpot and Degree Heating Week data (NOAA CRW).
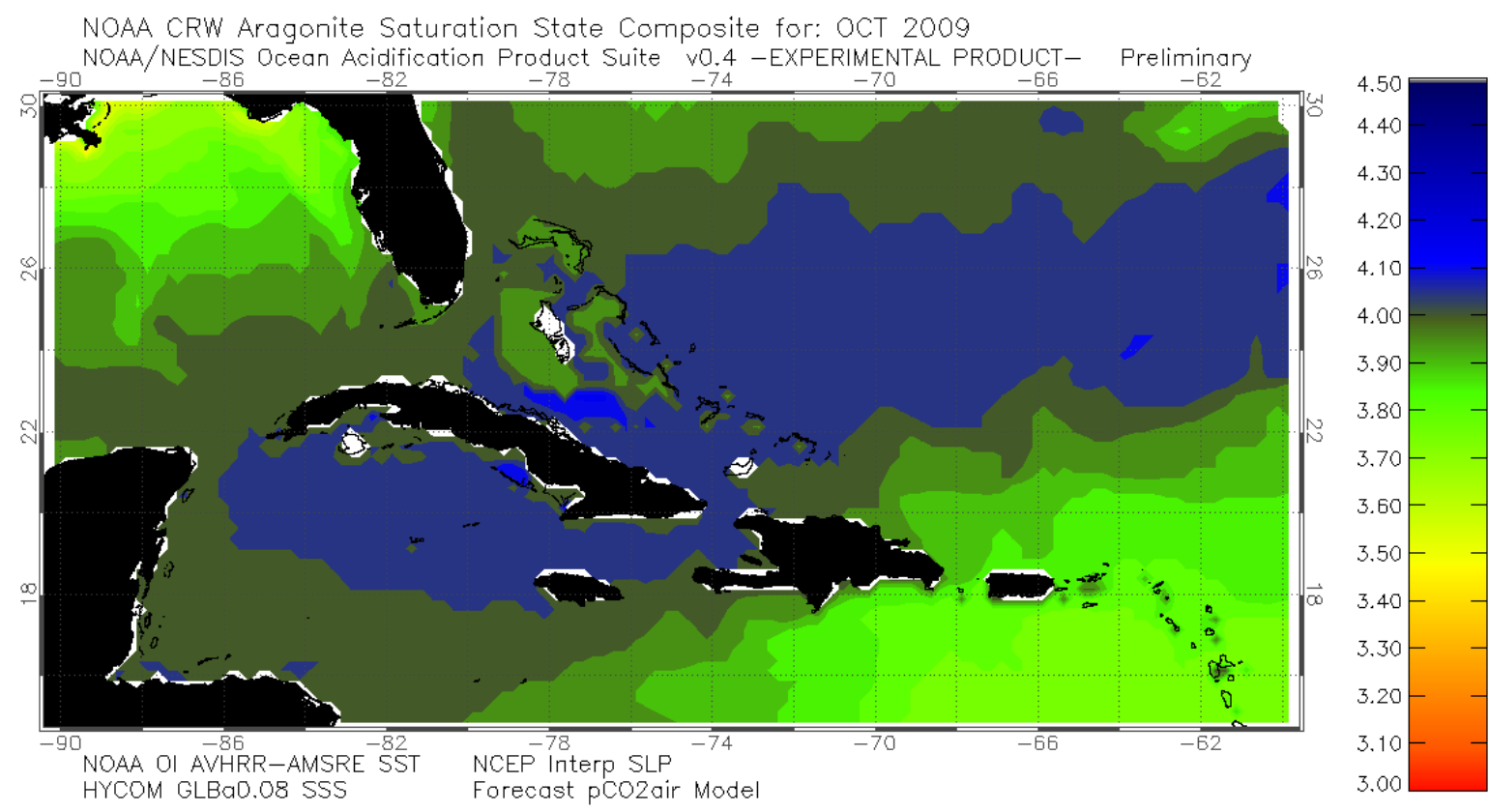

Figure 4. Map of NOAA CRW / AOML Ocean Acidification Product Suite showing the saturation state of the aragonitic form of calcium carbonate for October 2009 (NOAA CRW).

carbonate chemistry. CRW provides regional maps of a variety of acidification- relevant parameters including $\Omega_{\text {arg, }} \mathrm{pCO}_{2, \mathrm{sw}}$, total alkalinity, and carbonate and bicarbonate ion concentrations.

NOAA's ICON project has developed an ecoforecast [64 and 80] for the flux of water onto seaward reefs using observations from ICON moorings and highresolution $(\sim 1 \mathrm{~km})$ satellite fields. Alerts are generated when onset of variability of $\mathrm{T}$ and $\mathrm{S}$ is rapid and persists for multiple inertial periods. Integrated with satellite observations of SST and chl $a$, water flux onto the reef is determined. In situ $\mathrm{T}_{\text {air }}$, wave height, and wind velocity are analyzed by the ICON system to characterize onshore flux events and likely watermass sources, including wave setup at the reef crest $[67,81$ and 82], horizontal mixing [83], and upwelling. Research is underway to enhance these ecoforecasts to recognize spatial patterns in SST and chl $a$ imagery that are characteristic of distinct reef circulation scenarios. When patterns are recognized, additional 
alert rules will provide increased confidence and a regional context for decision-making.

CRW is using global climate models that forecast future ocean temperatures to develop predictions of coral bleaching months in advance [84]. NOAA is currently developing both mesoscale and coastal numerical hydrodynamic models to better understand many abiotic factors, such as circulation patterns [85 and 86], larval recruitment and transport, and impact of storm events; and to serve as a basis for fine-scale ecosystem modeling [29].

\section{GAPS - WHAT IS MISSING WITH I-CREOS?}

While coral reef observing systems are emerging in the Pacific (CREIOS, MCR-LTER and GBROOS) and Caribbean (ICON, CariCOOS), there are few interdisciplinary observing systems in the other large coral reef areas and even within these areas the observing systems are sparse and limited compared to the complexities of the ecosystems being monitored. Here we discuss a number of fundamental gaps that need to be overcome to provide the types of meaningful information required by managers and scientists to conserve coral reef ecosystems globally.

Until OceanObs'09, there had been a lack of recognition that biological observations must be an essential component of the Global Ocean Observing System (GOOS). In spite of this, a global network for biological observations on coral reefs has slowly developed (GCRMN) and serves as an essential foundation for the continued transition of I-CREOS into the GOOS. Due to the biogeophysical complexities of coral reef ecosystems and the high societal value placed upon them, this need to fully integrate biological observations into the GOOS infrastructure is paramount. Sensors and other technological advances to better observe biological processes over appropriate spatial and temporal scales must be developed to foster this integration.

The cost and complexity of coastal observing system infrastructure have been prohibitive. There is a need for increased coordination across our community and with technology vendors on the considerable research and development needed to reliably acquire scientifically valid observations of coral reefs. Realtime systems need to support Sensor Web Enablement protocols at the interface level and to support XMLbased data standards. Oceanographic instrument manufactures need to support the emerging set of data and interface standards so that instruments can be designed to serve data autonomously for direct utilization by users.

While coral reefs are too complex for observational conformity at all levels, there is a need to ensure data comparability between regions and programs.
Sampling regimes with agreed upon minimum sets of biological, physical, and chemical parameters to be collected using standardized methodologies, data schemas, quality control, datums and sensor calibrations should be developed with inputs from the coral reef, informatics, and observational communities.

While some physical sensors can presently be deployed for long periods (> 6 months), many sensors, particularly optical and wet-chemistry sensors for biological applications, require frequent maintenance that prevent long-term observations in many areas. New sensors currently under development include: biosensors to measure bacterial reactions to environmental toxins [87]; bio-film sensors to measure levels of water-based organic compounds; optical sensors to provide information about primary production and within organism cellular processes; and acoustic instruments, both passive and active, to provide information about community structure and abundance of fish and invertebrates and track larger organisms. Instrumentation to monitor carbonate chemistry and surveys to observe in situ calcification rate changes of corals and other reef-building organisms, as well as shifts in community structure and biodiversity, need to be advanced.

The final recurring gap is funding to support an expanded I-CREOS to other coral reef areas, e.g. Indian Ocean, Africa, Coral Triangle, and parts of Asia and Micronesia. There is a need to produce simple offthe-shelf self-contained observing systems that could be easily deployed and maintained with reasonable end-to-end costs. Additionally, human and social development priorities in these regions tend to overshadow technological enhancements in science and monitoring, and strong linkages of I-CREOS to these priorities are needed to enhance their utility in reef management.

Coral reefs are complex ecosystems and it is unrealistic to expect that observational systems will meet all needs. The issues facing coral reefs globally and the logistics of sampling and monitoring most of the coral reef areas means that automated "smart" observational systems will play a crucial role in how we monitor, manage and sustain reef ecosystems in the face of global threats, but there remain many immediate challenges.

\section{CONCLUSIONS}

Coral reefs are biologically diverse and highly valued ecosystems that are declining worldwide due to climate change and ocean acidification, overfishing, land-based sources of pollution, and other anthropogenic threats. To assist policy makers and resource managers at international, national, and local levels in effectively 
implementing ecosystem approaches to sustainable management and conservation of coral reefs and their biodiversity, it is necessary to have timely, unbiased integrated ecosystem observations about the conditions of coral reefs and the complex physical and biogeochemical processes supporting them. To provide these interdisciplinary ecosystem observations, an International network of Coral Reef Ecosystem Observing Systems (I-CREOS) is proposed by organizing and building upon some of the existing coral reef observation systems being developed globally. Examples of some developing observation systems (CREIOS, MCR-LTER, GBROOS, CREON, GCRMN, etc.) have been outlined in this paper to demonstrate some of the approaches and technologies available for acquiring biological, physical, and geochemical observations using combinations of: visual surveys, moored instrument arrays, spatial hydrographic and water quality surveys, satellite remote sensing, and hydrodynamic and ecosystem modeling. Initial efforts to integrate across scientific disciplines and observational approaches are now beginning to unfold (Fig. 5).

We envisage that I-CREOS will sit at the pinnacle of a larger coral reef monitoring and assessment network, providing the scientific validation and explanation for data obtained through basic government level monitoring, as encouraged by the GCRMN, and

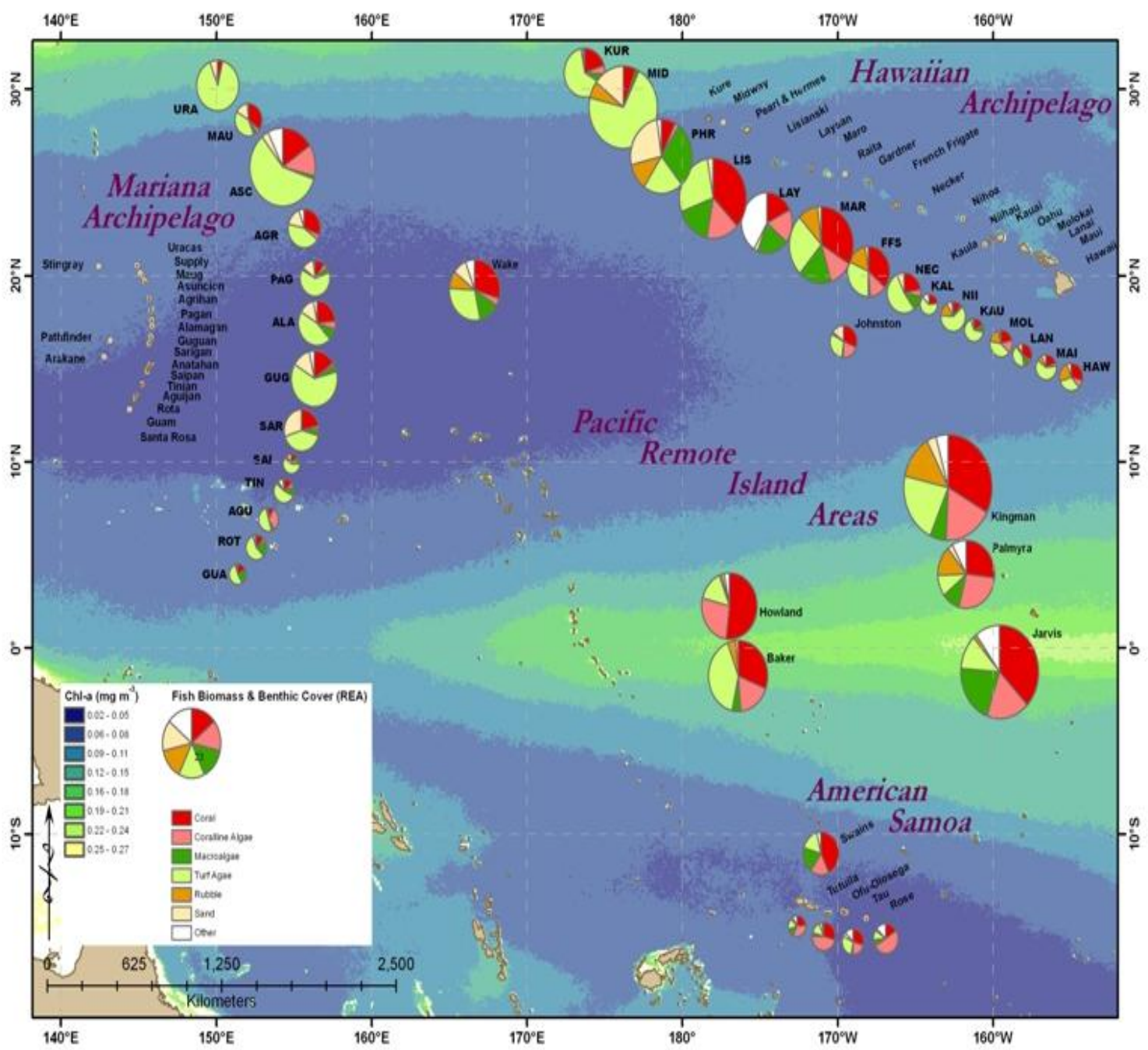

Figure 5. Pacific-wide integrated map of visual observations of fish biomass and benthic composition at coral reefs in the Pacific Islands overlaid on remotely-sensed chl a concentration from SeaWiFS (Sea-viewing Wide Field of View Sensor) ocean color. Sizes of pie charts indicate island-wide mean total reef fish biomass from NOAA Pacific RAMP rapid ecological assessment surveys over the period 2000-2008). Composition of pie charts indicates mean island-wide benthic composition from Pacific RAMP benthic towed-diver surveys over the period 2000-2008 (NOAA PIFSC 
community and volunteer monitoring, as encouraged by Reef Check and other volunteer networks. Such a nested network would permit greater coverage of the world's coral reef areas, and increase awareness of reef status and problems. Though, beyond the scope here, all monitoring activities should be complemented by socioeconomic assessments to ensure that the explanations are complete and conveyed to affected communities.

With common goals to maximize the versatility, accessibility, and robustness of the observations, the existing infrastructure and capacity provides a foundation by which increased global cooperation and coordination to develop common protocols and standards could naturally lead to a broader, more globally comprehensive I-CREOS. This fledgling network represents the early stages of an integrated ecosystem observing system for coral reefs capable of providing policy makers, resource managers, researchers, and other stakeholders with essential information products needed to assess various responses of coral reef ecosystems to natural variability and anthropogenic perturbations. The network's continued support and further development will ensure the increasing value of its data holdings and the network's observational and predictive capacity.

The proposed I-CREOS network fulfills the UNESCO (United Nations Educational Scientific and Cultural Organization) Strategic Design Plan for the Coastal Component of the GOOS mandate to "increase in our ability to detect and predict the changes that are occurring in coastal ecosystems" particularly addressing the "lack of spatially and temporally synoptic observations of key physical, chemical, and biological variables." While significant challenges and gaps in the I-CREOS network remain, it demonstrably fulfills the requirements of an operational, integrated, interdisciplinary, coastal component of GOOS.

\section{ACKNOWLEDGEMENTS}

GBROOS is a geographic node of the Australian IMOS project and it is funded under the Australian Federal Government's National Collaborative Research Infrastructure Strategy (NCRIS) and by the Queensland State Government. The Moorea Coral Reef LTER site is funded by the U.S. National Science Foundation and the Gordon and Betty Moore Foundation. The ICON program is funded by NOAA's Coral Reef Conservation Program, NOAA's High Performance Computing and Communications office, and additionally works through Memoranda of Understanding with the governments of Jamaica and the Little Cayman Research Center. NOAA CREIOS and Pacific RAMP are funded by NOAA's Coral Reef Conservation Program. CReefs is funded by the Alfred P. Sloan Foundation. The manuscript contents are solely the opinions of the authors and do not constitute a statement of policy, decision, or position on behalf of NOAA or the U.S. Government.

\section{REFERENCES}

1. Reaka-Kudla, M.L. (1997). The global biodiversity of coral reefs: A comparison with rain forests. In Biodiversity II: Understanding and protecting our biological resources, Reaka-Kudla, M.L., Wilson, D.E. \& Wilson, E.O., Eds., Joseph Henry Press, Washington, DC, p. 83-108.

2. Small, A.M., Adey, W.H. \& Spoon, D. (1998). Are current estimates of coral reef biodiversity too low? The view through the window of a microcosm. Atoll Research Bulletin 458, 1-20.

3. Moberg, F. \& Folke, C. (1999). Ecological goods and services of coral reef ecosystems. Ecological Economics 29, 215-233.

4. Cesar, H.S.J., Ed. (2000). Collected Essays on the Economics of Coral Reefs, CORDIO, Kalmar, Sweden.

5. Bengtsson, J., Angelstam, P., Elmqvist, T., Emanuelsson, U., et al. (2003). Reserves, resilience and dynamic landscapes. Ambio 32(6), 389-396.

6. Bunce, L., Townsley, P., Pomeroy, R. \& Pollnac, R. (2000). Socioeconomic Manual for Coral Reef Management, Australian Institute of Marine Science, Townsville, Australia, $251 \mathrm{pp}$.

7. McField, M. \& Kramer, P.R. (2007). Healthy Reefs for Healthy People: A guide to indicators of reef health and social well-being in the Mesoamerican reef region, With contributions by M. Gorrez and M. McPherson, Franklin Trade Graphics, Miami, FL, 208 pp.

8. Samonte-Tan, G., Catzim, A., Haylock, D., Curado, I., et al. (in press). Socioeconomic and governance monitoring of marine management areas: A work in progress. Proceedings of the 11th International Coral Reef Symposium, Ft. Lauderdale.

9. Knowlton, N. (2001). The future of coral reefs. Proceedings of the National Academy of Sciences 98(10), 5419-5425.

10. Bellwood, D.R., Hughes, T.P., Folke, C. \& Nystrom, M. (2004). Confronting the coral reef crisis. Nature 429(6994), 827-833.

11. Wilkinson, C., Ed. (2008). Status of Coral Reefs of the World: 2008, Global Coral Reef Monitoring Network and Reef and Rainforest Research Centre, Townsville, Australia, 296 pp.

12. Jackson, J.B.C., Kirby, M.X., Berger, W.H., Bjorndal, K.A., et al. (2001). Historical overfishing and the recent collapse of coastal ecosystems. Science 293, 629-638.

13. McManus, J.W. (1997). Tropical marine fisheries and the future of coral reefs: A brief review with emphasis on Southeast Asia. Coral Reefs 16(5), S121-S127.

14. Lessios, H.A., Cubit, J.D., Robertson, D.R., Shulman, M.J., et al. (1984). Mass mortality of Diadema 
antillarum on the Caribbean coast of Panama. Coral Reefs 3(4), 173-182.

15. Harvell, C.D., Kim, K., Burkholder, J.M., Colwell, R.R., et al. (1999). Emerging marine diseases: Climatic links and anthropogenic factors. Science 285, 1505-1510.

16. McCulloch, M., Fallon, S.R., Wyndham, T., Hendy, E., et al. (2003). Coral record of increased sediment flux to the inner Great Barrier Reef since European settlement. Nature 421(6924), 727-730.

17. Hughes, T.P., Baird, A.H., Bellwood, D.R., Card, M., et al. (2003). Climate change, human impacts, and the resilience of coral reefs. Science 301, 929-933.

18. Hoegh-Guldberg, O., Mumby, P.J., Hooten, A.J., Steneck, R.S., et al. (2007). Coral reefs under rapid climate change and ocean acidification. Science 318(5857), 1737-1742.

19. Brown, B.E. (1997). Coral bleaching: Causes and consequences. Coral Reefs 16(5), S129-S138.

20. Hoegh-Guldberg, O. (1999). Climate change, coral bleaching and the future of the world's coral reefs. Marine and Freshwater Research 50, 839-866.

21. Kleypas, J.A., Buddemeier, R.W., Archer, D., Gattuso, J.P., et al. (1999). Geochemical consequences of increased atmospheric carbon dioxide on coral reefs. Science 284(5411), 118-120.

22. Feely, R.A., Sabine, C.L., Lee, K., Berelson, W., et al. (2004). Impact of anthropogenic $\mathrm{CO}_{2}$ on the $\mathrm{CaCO}_{3}$ system in the oceans. Science 305(5682), 362-366.

23. Gardner, T.A., Côté, I.M., Gill, J.A., Grant, A., et al. (2003). Long-term region-wide declines in Caribbean corals. Science 301, 958-960.

24. Pandolfi, J.M., Bradbury, R.H., Sala, E., Hughes, T.P., et al. (2003). Global trajectories of the long-term decline of coral reef ecosystems. Science 301(5635), 955-958.

25. U.S. Commission on Ocean Policy (2004). An Ocean Blueprint for the 21st Century, Final Report, Washington, DC, 676 pp.

26. Morgan, J.A. \& Waddell, J.E., Eds. (2009). NOAA Coral Reef Ecosystem Integrated Observing System (CREIOS) Workshops Report, NOAA Technical Memorandum CRCP 9, NOAA Coral Reef Conservation Program, Silver Spring, MD, 68 pp.

27. Global Coral Reef Monitoring Network Publications, accessed 2009 at http://www.gcrmn.org/publications.aspx.

28. Morgan, J. \& Co-Authors (2010). "NOAA Coral Reef Ecosystem Integrated Observing System (CREIOS): A Collaborative Ecosystem-Based Observing System" in these proceedings (Annex), doi:10.5270/OceanObs09.

29. Hoeke, R.K., Gove, J.M., Smith, E., Fisher-Pool, P., et al. (2009). Coral reef ecosystem integrated observing system: In situ oceanographic observations at the US Pacific islands and atolls. Journal of Operational Oceanography 2(2), 3-14(12).
30. Brainard, R.E., Asher, J., Gove, J., Helyer, J., et al., Eds. (2008). Coral Reef Ecosystem Monitoring Report for American Samoa: 2002 - 2006, NOAA NMFS Pacific Islands Fisheries Science Center Coral Reef Ecosystem Division, Honolulu, HI, 510 pp.

31. Lundblad, E., Miller, J., Rooney, J., Moews, M., et al. (2006). Mapping Pacific Island coral reef ecosystems with multibeam and optical surveys. Coastal GeoTools '05, Myrtle Beach, SC, p. 15.

32. Schroeder, R.E., Green, A., DeMartini, E.E. \& Kenyon, J. (2008). Long-term effects of a ship-grounding on coral reef fish assemblages at Rose Atoll, American Samoa. Bulletin of Marine Science 82(3), 345-364.

33. Kenyon, J.C., Aeby, G.S., Brainard, R.E., Chojnacki, J.D., et al. (2006). Mass coral bleaching on high-latitude reefs in the Hawaiian Archipelago. Atoll Research Bulletin 543, 505-524.

34. Vargas-Angel, B. (2009). Coral health and disease assessment in the U.S. Pacific Remote Island Areas. Bulletin of Marine Science 84(2), 211-227.

35. Preskitt, L.B., Vroom, P.S. \& Smith, C.M. (2004). A Rapid Ecological Assessment (REA) quantitative survey method for benthic algae using photoquandrats with Scuba. Pacific Science 58(2), 201-209.

36. Vroom, P.S., Page, K.N., Kenyon, J.C. \& Brainard, R.E. (2006). Algal-dominated reefs: Numerous reports suggest that reefs must be dominated by coral to be healthy, but many thriving reefs depend more on algae. American Scientist 94, 430-437.

37. Kenyon, J., Brainard, R., Hoeke, R., Parrish, F., et al. (2006). Towed-diver surveys, a method for mesoscale spatial assessment of benthic reef habitat: A case study at Midway Atoll in the Hawaiian Archipelago. Coastal Management 33(33), 339-349.

38. Kendall, M.S., Kruer, C.R., Buja, K.R., Christensen, J.D., et al. (2000). Methods Used to Map the Benthic Habitats of Puerto Rico and the US Virgin Islands, NOAA/NOS Biogeography Program Tech. Rpt., Silver Spring, MD, 45 pp.

39. Monaco, M.E., Friedlander, A.M., Caldow, C., Christensen, J.D., et al. (2007). Characterising reef fish populations and habitats within and outside the US Virgin Islands Coral Reef National Monument: A lesson in Marine Protected Area design. Fisheries Management and Ecology 14(1), 33-40.

40. Pittman, S.J., Hile, S.D., Jeffrey, C.F.G., Caldow, C., et al. (2008). Fish Assemblages and Benthic Habitats of Buck Island Reef National Monument (St. Croix, U.S. Virgin Islands) and the Surrounding Seascape: A characterization of spatial and temporal patterns, NOAA Technical Memorandum NOS NCCOS 71, Silver Spring, MD, 96 pp.

41. Jankulak, M., Hendee, J. \& Shoemaker, M. (in press). The instrumental architecture of a Coral Reef Early Warning System (CREWS) station. Proceedings of the 11th International Coral Reef Symposium, Ft. Lauderdale. 
42. Eakin, C.M., Lough, J.M. \& Heron, S.F. (2009). Climate variability and change: monitoring data and evidence for increased coral bleaching stress. In Coral Bleaching: Patterns, processes, causes and consequences, Van Oppen, M.H. \& Lough, J.M., Eds., Springer, Berlin, p. 41-67.

43. Gledhill, D.K., Wanninkhof, R. \& Eakin, C.M. (2009). Observing ocean acidification from space. Oceanography 22(4):48-59.

44. Bainbridge S.J. (2010) GBROOS - An Ocean Observing System for the Great Barrier Reef. pp. 529-533. In: Riegl B and Dodge R (eds) 11th International Coral Reef Symposium, Fort Lauderdale. National Coral Reef Institute, Nova Southeastern University.

45. Sweatman, H.P.A., Cheal, A.J., Coleman, G.J., Emslie, M.J., et al. (2008). Long-term Monitoring of the Great Barrier Reef, Status Report 8, Australian Institute of Marine Science, Townsville, Australia, 369 pp

46. Open Source DataTurbine Initiative, accessed 2009 at http://www.dataturbine.org/.

47. Obura, D.O., Tamelander, J. \& Linden, O., Eds. (2008). Ten Years After Bleaching: Facing the consequences of climate change in the Indian Ocean, CORDIO Status Report 2008, CORDIO, Mombasa, Kenya, 457 pp.

48. McClanahan, T.R., Ateweberhan, M., Graham, N.A.J., Wilson, S.K., et al. (2007). Western Indian Ocean coral communities: Bleaching responses and susceptibility to extinction. Marine Ecology Progress Series 337, 1-13.

49. Quod, J.P., Dahalani, Y., Bigot, L., Nicet, J.B., et al. (2002). Status for coral reefs at Réunion, Mayotte and Madagascar. In CORDIO Status Report 2002, CORDIO, p. $185-189$.

50. Masumoto, Y., Yu, W. \& Meyers, G. (in prep.). Observing Systems in the Indian Ocean.

51. Waddell, J.E. \& Clarke, A.M., Eds. (2008). The State of Coral Reef Ecosystems of the United States and Pacific Freely Associated States: 2008, NOAA Technical Memorandum NOS NCCOS 73, NOAA/NCCOS Cente for Coastal Monitoring and Assessment's Biogeography Team, Silver Spring, MD, 569 pp.

52. Lang, J.C., Ed. (2003). Status of Coral Reefs in the Western Atlantic: Results of initial surveys, Atlantic and Gulf Rapid Reef Assessment (AGRRA) Program, Atoll Research Bulletin, No. 496, 630 pp.

53. Brainard, R., Maragos, J., Schroeder, R., Kenyon, J., et al. (2005). The state of coral reef ecosystems of the Pacific Remote Island Areas. In The State of Coral Reef Ecosystems of the United States and Pacific Freely Associated States: 2005, Waddell, J.E., Ed. NOAA Technical Memorandum NOS NCCOS 11 , NOAA/NCCOS Center for Coastal Monitoring and Assessment's Biogeography Team, Silver Spring, MD, p. $338-372$.

54. Friedlander, A., Aeby, G., Balwani, S., Bowen, B., et al. (2008). The state of coral reef ecosystems of the Northwestern Hawaiian Islands. In The State of Coral Reef Ecosystems of the United States and Pacific Freely
Associated States: 2008, Waddell, J.E. \& Clarke, A.M., Eds., NOAA Technical Memorandum NOS NCCOS 73, NOAA/NCCOS Center for Coastal Monitoring and Assessment's Biogeography Team, Silver Spring, MD, p. 263-307.

55. Friedlander, A., Aeby, G., Brainard, R., Brown, E., et al. (2008). The state of coral reef ecosystems of the Main Hawaiian Islands. In The State of Coral Reef Ecosystems of the United States and Pacific Freely Associated States: 2008, Waddell, J.E. \& Clarke, A.M., Eds. NOAA Technical Memorandum NOS NCCOS 73, NOAA/NCCOS Center for Coastal Monitoring and Assessment's Biogeography Team, Silver Spring, MD, p. 219-253.

56. Holbrook, S.J., Brooks, A.J. \& Schmitt, R.J. (2002). Variation in structural attributes of patch-forming corals and patterns of abundance of associated fishes. Marine and Freshwater Research 53, 1045-1053.

57. Holbrook, S.J., Brooks, A.J. \& Schmitt, R.J. (2002). Predictability of fish assemblages on coral patch reefs. Marine and Freshwater Research 53, 181-188.

58. Lison de Loma, T., Osenberg, C.W., Shima, J.S., Chancerelle, Y., et al. (2008). A framework for assessing impacts of Marine Protected Areas in Moorea (French Polynesia). Pacific Science 62(3), 431-441.

59. Hodgson, G. (1999). A global assessment of human effects on coral reefs. Marine Pollution Bulletin 38, 345355 .

60. Brainard, R., Moffitt, R., Timmers, M., Paulay, G., et al. (2009). Autonomous reef monitoring structures (ARMS): A tool for monitoring indices of biodiversity in the Pacific Islands (Abstract). 11th Pacific Science Inter-Congres., Mar 2-6, 2009, Papeete, Tahiti, p. 197.

61. Lammers, M.O., Brainard, R.E., Au, W.W.L., Mooney, T.A., et al. (2008). An Ecological Acoustic Recorder (EAR) for long-term monitoring of biological and anthropogenic sounds on coral reefs and other marine habitats. Journal of the Acoustical Society of America 123(3), 1720-1728.

62. Sueur, J., Pavoine, S., Hamerlynck, O. \& Duvail, S. (2008). Rapid acoustic survey for biodiversity appraisal. PLoS ONE 3(12), e4065.

63. Warner, M.E., Fitt, W.K. \& Schmidt, G.W. (1999). Damage to photosystem II in symbiotic dinoflagellates: A determinant of coral bleaching. Proceedings of the National Academy of Science, USA 96, 8007-8012.

64. Fitt, W.K., Brown, B.E., Warner, M.E. \& Dunne, R.P. (2001). Coral bleaching: Interpretation of thermal tolerance limits and thermal thresholds in tropical corals. Coral Reefs 20(1), 51-65.

65. Dunne, R.P. \& Brown, B.E. (2001). The influence of solar radiation on bleaching of shallow water reef corals in the Andaman Sea, 1993-1998. Coral Reefs 20(3), 201-210.

66. Manzello, D.P., Warner, M.E., Stabenau, E., Hendee, J.C., et al. (2009). Remote monitoring of chlorophyll fluorescence in two reef corals during the 2005 
bleaching event at Lee Stocking Island, Bahamas. Coral Reefs 28, 209-214.

67. Hendee, J.C., Gramer, L., Kleypas, J., Manzello, D., et al. (2007). The Integrated Coral Observing Network: Sensor solutions for sensitive sites. ISSNIP IEEE 2007: Proc 3rd Int'l Conf on Intelligent Sensors, Sensor Networks and Information Processing, Dec. 3-7, 2007, Melbourne, Australia, p. 669-673.

68. Hendee, J.C., Humphrey, C. \& Moore, T. (1998). A datadriven expert system for producing coral bleaching alerts. Proceedings, 7th International Conference on the Development and Application of Computer Techniques to Environmental Studies, Las Vegas, Nevada, November 10-12, 1998, p. 139-147.

69. Hendee, J.C., Stabenau, E., Florit, L., Manzello, D., et al. (2006). Infrastructure and capabilities of a near real-time meteorological and oceanographic in situ instrumented array, and its role in marine environmental decision support. In Remote Sensing of Aquatic Coastal Ecosystem Processes, Richardson, L.L. \& LeDrew, E.F., Eds., Kluwer Academic Press, p. 135-156.

70. Steinberg, C. (2007). Impacts of climate change on the physical oceanography of the Great Barrier Reef. In Climate Change and the Great Barrier Reef, Johnson, J.E. \& Marshall, P.A., Eds., Great Barrier Reef Marine Park Authority \& Australian Greenhouse Office, p. 5174.

71. Hench, J.L., Leichter, J.J. \& Monismith, S.G. (2008). Episodic circulation and exchange in a wave-driven coral reef and lagoon system. Limnology and Oceanography 53(6), 2681-2694.

72. Ogden, J.C., Porter, J., Smith, N., Szmant, A., et al. (1994). A long-term interdisciplinary study of the Florida Keys seascape. Bulletin of Marine Science 54(3), 1059-1071.

73. Manzello, D. (2004). A decade of SEAKEYS data: SST trends and patterns. In The Effects of Combined Sea Temperature, Light, and Carbon Dioxide on Coral Bleaching, Settlement, and Growth: The first annual Combined Effects Think Tank to support CREWS modeling, Hendee, J.C., Ed. NOAA Research Special Report, Miami, FL, p. 35-36.

74. Strong, A.E., Liu, G., Meyer, J., Hendee, J.C., et al. (2004). Coral Reef Watch 2002. Bulletin of Marine Science 75(2), 259-268.

75. Hendee, J.C., Liu, G., Strong, A., Sapper, J., et al. (2002) Near real-time validation of satellite sea surface temperature products at Rainbow Gardens Reef, Lee Stocking Island, Bahamas. 7th International Conference on Remote Sensing for Marine and Coastal Environments, p. 9.

76. Liu, G., Strong, A.E., Skirving, W.J. \& Arzayus, L.F. (2006). Overview of NOAA Coral Reef Watch Program's near-real-time satellite global coral bleaching monitoring activities. Proceedings of the 10th International Coral Reef Symposium, Okinawa, 17831793.
77. Maynard, J.A., Anthony, K.R.N., Marshall, P.A. \& Masiri, I. (2008). Major bleaching events can lead to increased thermal tolerance in corals. Marine Biology 155, 173-182.

78. Elvidge, C.D., Dietz, J.B., Berkelmans, R., Andréfouët, S., et al. (2004). Satellite observation of Keppel Islands (Great Barrier Reef) 2002 coral bleaching using IKONOS data. Coral Reefs 23(3), 461-462.

79. Gledhill, D.K., Wanninkhof, R., Millero, F.J. \& Eakin, M. (2008). Ocean acidification of the Greater Caribbean Region 1996-2006. Journal of Geophysical Research 113, C10031.

80. Hendee, J., Gramer, L., Manzello, D. \& Jankulak, M. (in press). Ecological forecasting for coral reef ecosystems. Proceedings of the 11th International Coral Reef Symposium, Ft. Lauderdale.

81. Wolanski, E., Jupp, D.L.B. \& Pickard, G.L. (1986). Currents and their interactions with coral reefs. Oceanus 29, 83-89.

82. Jago, O.K., Kench, P.S. \& Brander, R.W. (2007). Field observations of wave-driven water-level gradients across a coral reef flat. Journal of Geophysical Research 112, C06027.

83. Haus, B.K., Wang, J.D., Rivera, J., Martinez-Pedraja, J., et al. (2004). Southeast Florida Shelf circulation and volume exchange: Observations of $\mathrm{km}$-scale variability. Estuarine, Coastal And Shelf Science 59(2), 277-294.

84. Liu, G., Matrosova, L.E., Penland, C., Gledhill, D.K., et al. (in press). NOAA Coral Reef Watch Coral Bleaching Outlook System. Proceedings of the 11th International Coral Reef Symposium, Ft. Lauderdale.

85. Heron, S.F., Metzger, E.J. \& Skirving, W.J. (2006). Seasonal variations of the ocean surface circulation in the vicinity of Palau. Journal of Oceanography 62(4), 413-426.

86. Gramer, L.J., Johns, E.M., Hendee, J.C. \& Hu, C. (in press). Characterization of biologically significant hydrodynamic anomalies on the Florida Reef Tract. Proceedings of the 11th International Coral Reef Symposium, Ft. Lauderdale.

87. Rodriguez-Mozaz, S., Marco, M., Lopez de Alda, M. \& Barceló, D. (2004). Biosensors for environmental applications: future development trends. Journal of Pure and Applied Chemistry 76(4), 723-752. 